\title{
Exploring the Role of Size in Use Behaviour of Knowledge Management System: An Australian Study
}

\author{
Jun Xu \\ Southern Cross Business School \\ Southern Cross University, Australia \\ Mohammed Quaddus \\ Graduate School of Business \\ Curtin University, Australia
}

\begin{abstract}
This paper reports a recent study investigating the role of business size in use behaviour of knowledge management system. A knowledge management system use behaviour model was developed from Ventatash et al.'s ${ }^{1}$ unified theory of acceptance \& use of technology model, and the developed model was tested by quantitative analysis of a collected dataset in Western Australia via partial least square (PLS) approach. The results of this study indicate there are no significant relation between business size and the use of knowledge management system. This is contrary to the traditional literature on information systems which generally reports that size does matter in information systems/information technology adoption and diffusion. The implications of the study are highlighted and future research directions are discussed.
\end{abstract}

Keywords: Knowledge management; Knowledge management systems; Initiation; Use behaviour; Business size; Partial Least Square (PLS)

\section{Introduction}

Human civilizations have been preserving and passing knowledge from generation to generation for a better understanding of the past and therefore, the future. A lot of research has been done on different aspects of knowledge management, including general knowledge management studies; linking knowledge management with business; processes of knowledge management; factors influencing the success of knowledge management; technologies, tools, methods and techniques for knowledge management; evaluation of knowledge management performance; and knowledge management in different national and cultural contexts ${ }^{2}$. However the majority of them have been focusing on large organizations ${ }^{3}$. The literature on knowledge management in different sizes of business (such as between large businesses (with more than 200 staff) and small \& medium enterprises) is very limited. This research is aimed to address this gap and it investigates the role of business size in knowledge management practices by addressing the research question of "Does business size influence use behaviour of knowledge management system?"

This paper is organized as follows. The background of the research is presented next. This is followed by the description of development of the proposed hypotheses tested in this study. The results are presented and discussed in detail next. Finally conclusions and future research directions are presented.

\section{Background}

\subsection{Knowledge management and knowledge management systems}

Knowledge management is "an approach to adding or creating value by more actively leveraging the know- 
how, experience, and judgment [that] reside within and, in many cases, outside of an organization"(Ruggles $\left.1980^{4}\right)$. The above definition highlights important elements of knowledge management. The know-how aspect of knowledge management emphasizes explicit knowledge, which can be easily captured and codified ${ }^{5}$. On the other hand, the experience and judgment aspects of knowledge management reflect tacit or implicit knowledge, which is difficult to capture and formalize ${ }^{5}$. The definition also emphasizes that the primary purpose of knowledge management is to add or create value. Knowledge management systems such as intranets, best practice databases, corporate knowledge directories, corporate information portals, knowledge networks and maps and other applications (i.e., online communities, social networks, internal wikis, internal prediction markets, internal Google-type search engines, blogs, discussion boards, feedback forums, online live communication systems, virtual organizations \& teams), can also be used to support and enhance knowledge management activities and facilitate the sharing of both tacit and explicit knowledge ${ }^{6}$.

There are four modes of tacit and explicit knowledge creation processes $^{7}$. The four processes are: socialisation, externalisation, combination, and internalisation (see Figure 1).

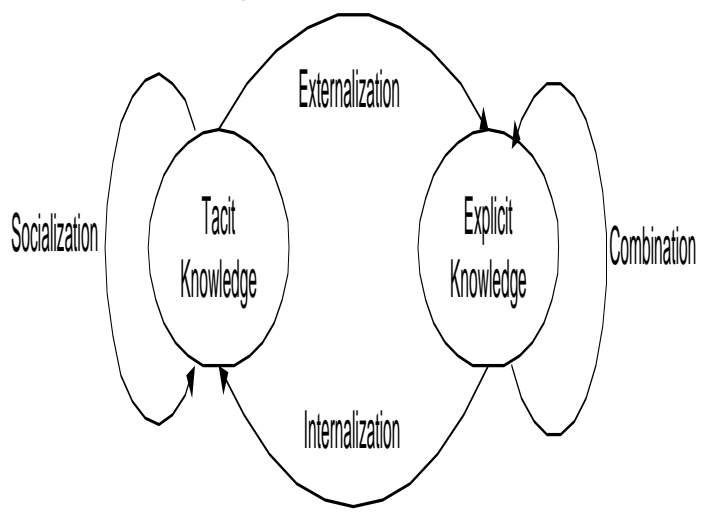

Figure1 Four knowledge creation processes (Soruce: adapted from Bolloju et al. ${ }^{8}$ )

Socialisation refers to the conversion of tacit knowledge to tacit knowledge that is hidden knowledge and hard to communicate, such as knowledge sharing among individuals through face-to-face contact such as interviews, focus group, conversations in the lunch time and coffee/tea break, on-the-job training, master-fellow- relationships, formal and informal networks, and brainstorming. In this knowledge creation process, information systems can be useful in connecting people and creating and sustaining knowledge communities through teleconferencing technologies, including desktop videoconferencing tools; online live communication systems and virtual organizations and teams; and internal knowledge marketplaces, predication markets, talent marketplaces ${ }^{9,10}$. Externalisation is the process of converting tacit knowledge to explicit knowledge in the form of metaphors, analogies, hypothesis, and models, such as articulating tacit knowledge, such as experience, insight, judgment, problem solving skills, obtained through observation, imitation, and practice into the format that can be used for future purpose and by who need it. The creation of explicit knowledge can be dramatically enhanced by information systems including groupware tools and electronic mail as well as wikis, blogs, discussion boards, feedback forums, and virtual organizations and teams 9 .

Internalisation is a process in which explicit knowledge is absorbed and becomes part of tacit knowledge. This process regards the activities of applying knowledge in practice and reflects the concept of learning by doing (i.e. internalising the new or shared explicit knowledge through hands-on practice). Also documented knowledge can be helpful in this process, such as learning from best practice databases. Applications such as data mining tools, OLAP, internal Google-type search engines, internal predication markets, internal eBay type knowledge auction sites, for enhancing decision-makers' ability to make sense out of explicit information, especially in the presence of complex sets of data, can be very effective in this regard ${ }^{9}$.

\subsection{The role of business size in knowledge management}

Past research has reported the impact of size in the adoption of technology. For example, Kimbley and Evansiko $^{11}$ suggest that adoption of technical innovation tend to spread widely in large organizations. Similarly Thong and Yap ${ }^{12}$, Thong ${ }^{13}$ and Dasgupta et al. ${ }^{14}$ indicate that larger organizations are more likely to adopt information technology/information systems. Meanwhile according to Premkumar et al. ${ }^{15}$ larger organizations are more likely to adopt electronic data interchange (EDI). In addition, Bajwa and Floyd 
Lewis ${ }^{16}$ find out larger organizations are likely to adopt more collaborative technologies than their smaller counterparts while Ko et al. ${ }^{17}$ point out that large organizations are more likely to adopt customer relationship management strategy. Furthermore, Rogers ${ }^{18}$ points out business size has positive impact on organizational innovativeness, which is the organization's willingness to adopt the innovation. In relation to knowledge management system, Sarvary ${ }^{19}$ suggests that large firms with large customer base tend to perceive a knowledge management system more useful and have a better chance to apply knowledge management system to build sustain competitive advantage. Davenport and Prusak ${ }^{20}$ suggest that size and dispersion of organizations are related to their adoption decision of knowledge management systems. A larger and global enterprise is more likely to embark on knowledge management systems to "know what they know" and use that knowledge effectively. On the other hand, Serenko, Bontis and Hardie ${ }^{3}$ propose that the size of organizational unit has negative relation with the effectiveness of internal knowledge flow and with the intra-organizational knowledge sharing.

In the meantime, there exists an argument that large organizations may not be the most innovative sources of knowledge management. Sveiby ${ }^{21}$ says that "If we wish to see the future of corporate Australia, we don't need a crystal ball or sophisticated forecasts by economists. All we need to do is to visit some of the small fastest growing and most successful knowledge companies. The management styles they are pioneering and the strategies they are pursuing will be the case stories taught in the standard curriculum of the management schools of Australia". In addition, after studying five large businesses (size of the company varies from 200 staff to over 4000 staff) and ten small and medium enterprises (size of the company varies from 7 staff to around 200) in Australia, Xu et al. ${ }^{22}$ suggest that there are no major differences in significant factors of knowledge management between large and small and medium businesses across different industry. "Top Management Support/ Leadership", "Organizational Structure", and "Organizational Culture" are critical for knowledge management in businesses of different sizes. In today's highly competitive market environment, all the companies, including small businesses which could lack a clear understanding of knowledge management and could be slow in adopting knowledge management $^{23,}{ }^{24}$, have to practice knowledge management even though there could be differences in scope, scale and implementation for different $\operatorname{organizations}^{23}$, and it is quite impossible to survive the severe competition without managing knowledge in the knowledge economy. Perhaps larger companies are practising knowledge management more consciously and systematically than smaller businesses. And the former could also use more or more available advanced information technologies (such as search engines, blogs, collaborative filtering applications, recommendation systems, online learning software, social networks, wikis \& other online collaborative tools) to manage their knowledge.

\subsection{The Research Model}

The research model of this study is developed from Venkatesh et al.'s ${ }^{1}$ Unified Theory of Acceptance \& Use of Technology (UTAUT) model, which is built from model(s) by Ajzen \& Fishbein ${ }^{25}$, Davis ${ }^{26}$, and Rogers ${ }^{18}$. The UTAUT model works around the basic concept of Reactions to using information technology $>>>$ Intention to use information technology $>>>$ Actual use of information technology, this simple model is generic in nature and is likely to be applicable, with some adjustments, in various innovation diffusion processes. Built on Venkatesh et al.'s ${ }^{1}$ UTAUT model, this study proposed a knowledge management system use behaviour model (see Figure 2 ). There are six factors in the model, namely performance expectancy, effort expectancy, social influence, facilitating conditions, initiation, and use behaviour of knowledge management system. Organizational size was used as a moderating variable.

Performance Expectancy is defined as the belief that knowledge management system will attain gains in job performance $^{1}$. Some expected benefits of use of knowledge management system include: (1) having benefits to decision makers; (2) being more effective in jobs, (3) being more creative in jobs, (4) having productivity enhancement, (5) achieving cost and time reduction, (6) realizing increased knowledge building, (7) avoiding repeating the same mistakes, (8) providing better customer services, and (9) gaining high-tech image. Effort Expectancy is defined as the degree of ease associated with the use of knowledge management 
system ${ }^{1}$. Dimensions of Effort Expectancy include (1) being simple to learn and use, (2) being cheap to learn and use, (3) being quick to get required knowledge, and (4) being accessible from anywhere anytime.

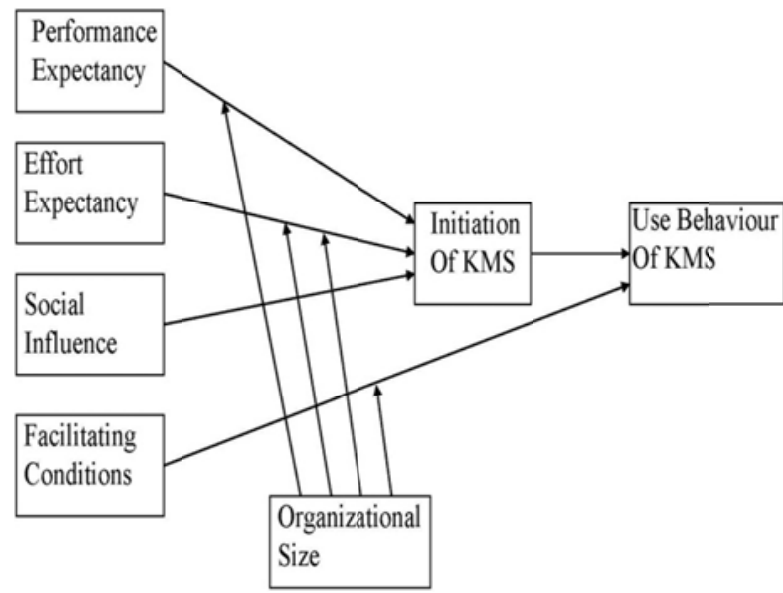

Figure 2: A knowledge management system (KMS) use behaviour model

Social Influence refers to the influence of others (such as (1) peer pressure, (2) following leaders' lead, (3) respected people's influence, (4) superior's encouragement, and (5) subordinate's encouragement) on adoption and use of knowledge management system $^{1}$. Facilitating Conditions refer to the existence of organizational and technical infrastructure to support knowledge management system ${ }^{1}$, including (1) people's experience and skill, (2) understanding of organizational knowledge, (3) organizational structure supporting knowledge management system, (4) organizational culture supporting knowledge management system, (5) IS/IT infrastructure supporting knowledge management system, (6) support from IS/IT department, (7) business processes supporting knowledge management system, (8) top management initiative, (9) top management support, (10) people's innovativeness, and (11) effective knowledge reuse.

Initiation of knowledge management system refers to the background work and adjustments to embrace knowledge management system and involves activities of (1) establishing that knowledge management system is the ideal solution, (2) conducting research on knowledge management system, (3) allocating budget, (4) appointing a knowledge champion, (5) building supporting infrastructure for knowledge management system introduction, and (6) having organizational adjustments (e.g., adjustments to business processes). Use Behaviour of knowledge management system refers to implementation and diffusion of knowledge management system and look at areas of (1) routine use of knowledge management system, (2) consistently satisfying users' needs, (3) making using knowledge management system an integral part of business process, (4) ensuring the use of knowledge management system supporting users' working style, (5) making adjustments to business processes for knowledge management system implementation, (6) discouraging old means of capturing and using knowledge, (7) having rigorous procedures for using knowledge management system, and (8) monitoring the usage of knowledge management system. On a related note, Business/Organizational Size refers to the number of employees.

\section{Hypotheses Development}

Links in the research model (Figure 2) represent the hypotheses. The model thus has five hypotheses. In the following sections, those five hypotheses are discussed.

Knowledge management systems can provide benefits to organization in decision-making, effectiveness, creativity, productivity, cost \& time reduction, knowledge building, avoiding same mistakes, and better customer services ${ }^{27}$. Bansler and $\operatorname{Havn}^{28}$ suggest that expectations/perceptions are key factors in determining organizations' and individuals' decision about whether or not to adopt a new knowledge management system. Gray $^{29}$ believes that individuals' perceived value of knowledge management systems has direct relationship with their use of knowledge management systems. He proposes that increased solution effectiveness through use of knowledge management systems will lead to the enhanced perceptions of usefulness of knowledge management systems, which is linking to the higher level use of the systems. Meanwhile, Ajzen \& Fishbein's ${ }^{25}$ Theory of Reasoned Action (TRA) and Davis ${ }^{26}$ Technology Acceptance Model (TAM) propose direct impacts of perceived usefulness on intentions to use the systems. In addition, past studies (e.g., Kimbley \& Evansiko ${ }^{10}$; Rogers $^{18}$; Thong \& Yap $^{12}$; Premkumar ${ }^{15}$; Davenport \& Prusak ${ }^{20}$; Dasgupta et al. ${ }^{14}$; Sarvary ${ }^{19}$; Thong $^{13}$; Bajwa \& Floyd Lewis ${ }^{16}$; Ko et al. ${ }^{17}$ ) have reported the impact of size in the adoption of 
technology. Furthermore Venkatesh et al. ${ }^{1}$ suggest that the influence of performance expectancy on behavior intention to use information technology is moderated by selected moderating influences. As per the above discussion, it is hypothesized that:

H1: The influence of expected performance of knowledge management system on initiation of knowledge management system will be moderated by business size, such that the effect will be stronger for larger organizations.

A knowledge management system has to be useful, otherwise organizations and individuals won't have interest to adopt or use it. On the other hand, a knowledge management system has to be ease of use and be user friendly, otherwise potential adopters (both organization and individuals) of a knowledge management system won't adopt or use the system even though it is useful, since this is human being's nature to use easier one (system) ${ }^{27}$. Thus ease of use is a very important factor. Knowledge management systems must have user-focus and take people's needs into consideration. Knowledge is useless if people are unable to use the knowledge management systems where it resides $i^{30}$. A knowledge management system must ensure that users can do what they need and what they want to do with the system. Robertson ${ }^{30}$ argues that when a knowledge management project involves the application of information technology, the usability/user-friendly plays an important role, he also suggests that a user-friendly knowledge management system is such a system, which is easy to learn, allows the users to be efficient in their work, prevents user's errors whenever possible, easy to remember how to use, and satisfies the user's needs thus they are happy with the way the system works. Meanwhile, Ajzen \& Fishbein's ${ }^{25}$ Theory of Reasoned Action (TRA) and Davis ${ }^{26}$ Technology Acceptance Model (TAM) propose perceived user-friendly/ perceived ease of use are important determinants of intentions to use the systems. In addition, past studies (e.g., Kimbley \& Evansiko ${ }^{10}$; Rogers $^{18}$; Thong \& Yap ${ }^{12}$; Premkumar ${ }^{15}$; Davenport \& Prusak $^{20}$; Dasgupta et al. ${ }^{14}$; Sarvary ${ }^{19}$; Thong ${ }^{13}$; Bajwa $\&$ Floyd Lewis ${ }^{16}$; Ko et al. ${ }^{17}$ ) have reported the impact of size in the adoption of technology. Furthermore Venkatesh et al. ${ }^{1}$ suggest that the influence of expected efforts on behavior intention to use information technology is moderated by selected moderating influences. As per the above discussion, it is hypothesized that:

H2: The influence of expected effort to use knowledge management system on initiation of knowledge management system will be moderated by business size, such that the effect will be stronger for larger organizations.

Subject norms describe the social influence that may affect a person's intention to use knowledge management system. People often take action based on their perceptions of what others think they should do. Past studies (such as Thompson, Higgins \& Howell ${ }^{31}$; Liker \& Sindi ${ }^{32}$; Lucas \& Spitler $^{33}$ ) find that subject norms are positively associated with individual's acceptance of new technology. Meanwhile subject norms have been found to be more important in the early stages of innovation implementation, when users have limited direct experience from which to develop attitudes and perceptions (Hartwick \& Barki ${ }^{34}$; Taylor \& Todd $^{35}$ ). Huber ${ }^{36}$ suggests that there is considerable ignorance in the literature on the impacts of the socialpsychological forces, such as the need to adhere to social norms, the need to comply with organizational norms (the right thing to do), the need for recognition, on knowledge sharing and participation in knowledge management systems. As a result, there is a great need for future research to explore this area. Gray $^{29}$ suggests that knowledge management systems use may be a selfreinforcing process. Once the value of such systems is established, the system use is likely to become routine and thus lead to widespread acceptance and use. Quaddus and $\mathrm{Xu}^{27}$ point out that people's use of knowledge management systems can be influenced by others, such as leaders, peers, and respected people. In addition, past studies (e.g., Kimbley \& Evansiko ${ }^{10}$; Rogers $^{18}$; Thong \& Yap ${ }^{12}$; Premkumar ${ }^{15}$; Davenport \& Prusak $^{20}$; Dasgupta et al. ${ }^{14}$; Sarvary ${ }^{19}$; Thong ${ }^{13}$; Bajwa $\&$ Floyd Lewis ${ }^{16}$; Ko et al. ${ }^{17}$ ) have reported the impact of size in the adoption of technology. Furthermore Venkatesh et al. ${ }^{1}$ suggest that the influence of social influence on behavior intention to use information technology is moderated by selected moderating influences. As per the above discussion, it is hypothesized that:

H3: The influence of social influence on initiation of knowledge management system will be moderated by 
business size, such that the effect will be stronger for larger organizations.

Gold, Malhorta and Segars ${ }^{37}$ suggest that Knowledge infrastructure capability (technology, structure, and culture) along with knowledge process capability (acquisition, conversion, application, and protection) is essential organizational capabilities or precondition for effective knowledge management; and knowledge management capabilities, consisting of knowledge infrastructure and knowledge processes, have direct and positive influence on organizational effectiveness. Management and leadership play critical roles in knowledge management ${ }^{41}$, 42. Management provides vision and energy to stimulate and sustain effective knowledge management practices and systems. Leaders have direct impact on the organization's culture and its knowledge management approaches. Without management's commitment and emphasis on knowledge management, people won't take it seriously ${ }^{43}$. Those at the top of an organization should have to find the knowledge needs of the business. Simply investing money in IT only can produce more examples of KM failures and waste of investment. Leaders have to take account issues such as culture, structure, process, training and development. More attention should be given to people since businesses make profits through selling and effectively using their knowledge (tacit knowledge) ${ }^{21,44}$. One important challenge for leaders is how they can embed knowledge into people's day-to-day work to help them do their jobs more effectively and efficiently ${ }^{45}$. Besides being role models for learning and knowledge sharing, leaders are responsible for creating a climate of trust where people can share knowledge with confidence ${ }^{41}$. And support from top management is crucial for the success of knowledge management ${ }^{27}$. For example, the leadership process in General Electric (GE) is all about sharing knowledge and creating knowledge. The top management in GE has focused on the importance of sharing knowledge. The knowledge sharing practice starts at the top ${ }^{44}$.

Organizational culture has been increasingly recognized as a major barrier and a critical success factor to knowledge management $t^{37,42,46,47,48}$. Organizations have to create an environment where people feel comfortable and are willing to share their knowledge. A knowledge- oriented culture challenges people to share knowledge throughout the organization ${ }^{20,37}$. In the meantime, the benefits of knowledge management need to be demonstrated, and knowledge-sharing practices should be rewarded with tangible (e.g., financial rewards) and intangible (e.g., recognition) incentives ${ }^{43}$. Organizations need to have suitable structure for knowledge sharing and for effective management of their knowledge assets $^{48,49,50}$, and those with flexible and organic structure are more likely to achieve the perceived benefits of knowledge management than those organizations that are rigid and bureaucratic ${ }^{37}$. Organizations with a rigid structure must be prepared to re-engineer its organizational structure to facilitate effective knowledge management.

The unconditional support of top management, knowledge-sharing culture, and reward system are also some important factors for successful implementation and effective use of knowledge management system ${ }^{38}$. The usefulness of a knowledge management system is associated with the incentives provided to employees to make long-term investments in their own human capital $^{39}$. Davenport, Long and Beers ${ }^{40}$ convey the same view. They suggest that one of most important determinants of the successful knowledge management projects is a knowledge-friendly culture where people have a positive orientation toward knowledge, people are not inhibited in sharing knowledge, and the knowledge management project fits with the existing culture. In addition, Quaddus and $\mathrm{Xu}^{27}$ point out organizational factors, such as business growth, organizational structure, organizational culture, information technology infrastructure, business processes, information technology/information systems department, and business size, have influence on the perceived value of knowledge management system, which in turn will have impact on adoption and use of knowledge management system. Meanwhile, organizations need to work hard on persuading and educating people to use the knowledge management system. The most difficult part in implementing knowledge management system from cultural perspective is making people to understand that sharing knowledge and using the system will bring benefits not only to the organization but also to themselves ${ }^{51}$. 
Meanwhile, previous studies (e.g., Kimbley \& Evansiko $^{10}$; $\operatorname{Rogers}^{18}$; Thong \& Yap ${ }^{12}$; Premkumar ${ }^{15}$; Davenport \& Prusak ${ }^{20}$; Dasgupta et al. ${ }^{14}$; Sarvary ${ }^{19}$; Thong $^{13}$; Bajwa \& Floyd Lewis ${ }^{16}$; Ko et al. ${ }^{17}$ ) have reported the impact of size in the adoption of technology. Furthermore Venkatesh et al. ${ }^{1}$ suggest that the influence of facilitating conditions on behavior intention to use information technology is moderated by selected moderating influences. As per the above discussion, it is hypothesized that:

H4: The influence of facilitating conditions on use behavior of knowledge management system will be moderated by business size, such that the effect will be stronger for larger organizations.

After organizations implement the knowledge management systems in the whole organization, people in the organization start to use the systems. At this stage, organizations face another challenge -how to make sure people's sustained use of knowledge management systems. Sustained use of knowledge management systems means that people will use the systems and using systems has become a part of business as well as a part of people's life. For the purpose of achieving people's sustained use of the systems, organizations should promote best practices of knowledge management and knowledge management systems, keep on providing what people want in knowledge management systems, encourage people's more usage and involvement in knowledge management and knowledge management systems, make using the systems as a part of the business, and make using the systems a part of people's life in organization. Gray ${ }^{29}$ suggests that increased employee knowledge specialization arising from the use of knowledge management systems will result in the increased use of the systems. He proposes that increased solution effectiveness through the use of knowledge management systems will lead to the enhanced perceptions of usefulness of knowledge management systems, which links to the higher level use of knowledge management systems.

At the same time, past studies (such as Lewin ${ }^{52}$; Nolan $^{53}$; Cash \& McLeod ${ }^{54}$; Gerwin ${ }^{55}$; Huff \& Munro ${ }^{56}$ Kwon \& $\mathrm{Zmud}^{57}$; Kanter ${ }^{58}$; Walton ${ }^{59}$; Brancheau \& Webtherbe $^{60}$; Cooper \& Zmud ${ }^{61}$; Nilakanta \& Scamell ${ }^{62}$; Applegate $^{63}$; Grover \& Goslar $^{64}$; Rai ${ }^{65}$; Rogers ${ }^{18}$; Carter et al. $^{66}$ ) provide some various stage models of innovation diffusion, but they basically start with the initiation stage and finish with the diffusion stage. For example, Kwon and $\mathrm{Zmud}^{57}$ design such a stage model for innovation implementation process of initiation $>>$ adoption $>$ adaptation $>$ acceptance $>$ use $>>$ incorporation. Furthermore Venkatesh et al. ${ }^{1}$ suggest that behavioral intention significantly influence use behavior of information technology. As per the above discussion, it is hypothesized that:

H5: Initiation of knowledge management system will have a significant positive influence on use behavior of knowledge management system.

\section{Research Design}

\subsection{Western Australia Survey}

The questionnaires were sent to 300 top companies (based on revenue) in Western Australia. These companies are selected from Dun \& Bradstreet database. There were 2 participants from each company, thus 600 respondents took part in the study. The criterion for selecting a respondent of the study is he/she has the best or most relevant knowledge of his/her firm's implementation and use of knowledge management system. 159 questionnaires were returned. 10 of them were found to be incomplete resulting in 149 valid responses. Thus final effective response rate was $24.8 \%$. Distribution of size (number of employees) can be seen in Table 1.

Table 1: Distribution of size

\begin{tabular}{ccccc}
\multicolumn{5}{c}{ Table 1: Distribution of size } \\
\hline & Frequency & Percentage & $\begin{array}{c}\text { Valid } \\
\text { Percentage }\end{array}$ & $\begin{array}{c}\text { Cumulative } \\
\text { Percentage }\end{array}$ \\
\hline$<$ & 50 & 33.6 & 33.6 & 33.6 \\
100 & & & & \\
$100-$ & 38 & 25.5 & 25.5 & 59.1 \\
300 & & & & 67.8 \\
$301-$ & 13 & 8.7 & 8.7 & 100.0 \\
500 & 48 & 32.2 & 32.2 & \\
$>$ & & & & \\
500 & 149 & 100.0 & 100.0 & \\
Total & 149 & & &
\end{tabular}

\subsection{Data Analysis via Partial Least Square}

The national survey data was analysed by Structural Equation Modelling approach of Partial Least Square technique using PLS-Graph 3.0. Before the data were analysed, it was necessary to assess its properties. Data 
were tested for assumption of multi-normality. Although the Kolomogorov-Smirnov normality test showed the distribution anomalies in all items, the skewness and kurtosis of each item fell within the acceptable range $( \pm 2)$. It is noted that Partial Least Square technique is especially appropriate for small sample analysis ${ }^{67}$. According to Barclay et al. ${ }^{68}$ Partial Least Square requires a minimum sample size that is ten times the greater of: (i) the number of items comprising the most complex formative construct, or (ii) the largest number of predictors leading to an endogenous (dependent) construct. We don't have any formative construct in our research model and in our case the largest number of predictors leading to an endogenous construct is 11 (Facilitating Conditions in the model). Thus this study requires a minimum sample size of 77 . Therefore 149 valid responses in Western Australia are appropriate for data analysis using partial least square. Reliability of factors in the model was measured by examining cronbach's $\alpha$. The cut-off point for reliability is normally taken as 0.7 . However 0.6 is acceptable for exploratory research ${ }^{69}$. This study is exploratory in nature since it is testing a revised model with knowledge management system as the case. Table 2 shows that all the latent variables have internal consistencies above 0.6, indicating that the constructs are internally consistent and hence reliable.

\begin{tabular}{cc}
\multicolumn{2}{c}{ Table 2: Reliability of Factors } \\
\hline Factors & Western Australia Data \\
\hline Performance Expectation & 0.841 \\
Effort Expectation & 0.684 \\
Social Influence & 0.786 \\
Facilitating Conditions & 0.871 \\
Initiation of KMS & 0.796 \\
Use Behaviour of KMS & 0.812 \\
\hline
\end{tabular}

\section{Results}

Table 3 and Table 4 report the results of Western Australia Survey using business size (number of employee) as moderating variable. It can be seen from $\mathrm{H} 1$ to $\mathrm{H} 4$ were not supported while H5 was supported.

Table 3: Results of Survey

\begin{tabular}{|c|c|}
\hline Predictor & Initiation \\
\hline \multicolumn{2}{|l|}{ Moderation: } \\
\hline $\begin{array}{c}\text { H1: Performance Expectancy X } \\
\text { Organizational Size (employee number) }\end{array}$ & $\begin{array}{c}0.362 \\
\text { (non-significant) }\end{array}$ \\
\hline $\begin{array}{l}\text { H2: Effort Expectancy X } \\
\text { Organizational Size (employee number) }\end{array}$ & $\begin{array}{c}0.592 \\
\text { (non-significant) }\end{array}$ \\
\hline
\end{tabular}

\begin{tabular}{|c|c|c|}
\hline $\begin{array}{r}\text { H3: Social Influen } \\
\text { Organizational Size (empl } \\
\text { F } \\
\text { (Sig) } \\
\text { Adj. R2 }\end{array}$ & yee number) & $\begin{array}{c}-0.986 \\
\text { (non-significant) } \\
9.049 \\
(0.00) \\
0.332 \\
\end{array}$ \\
\hline \multicolumn{3}{|c|}{ Table 4: Results of Survey (cont.) } \\
\hline Predictor & \multicolumn{2}{|c|}{$\begin{array}{l}\text { Use Behaviour of Knowledge } \\
\text { Management System }\end{array}$} \\
\hline \multicolumn{3}{|l|}{ Independent Variable } \\
\hline H5: Initiation & \multicolumn{2}{|r|}{$0.59 * * *$} \\
\hline \multicolumn{3}{|l|}{ Moderation: } \\
\hline $\begin{array}{c}\text { H4: Facilitating Conditions } \\
\text { X } \\
\text { Organizational Size } \\
\text { (employee number) }\end{array}$ & \multicolumn{2}{|c|}{0.009 (non-significant) } \\
\hline $\mathrm{F}$ & \multicolumn{2}{|c|}{$33.999 * * *$} \\
\hline$(\mathrm{Sig})$ & \multicolumn{2}{|c|}{$(0.00)$} \\
\hline Adj. R2 & \multicolumn{2}{|r|}{0.574} \\
\hline
\end{tabular}

\section{Conclusions and Future Research Directions}

This paper presents a study of developing and testing a model of knowledge management system use behaviour via analysing a collected dataset of top 300 Western Australian firms. The results of this study unveiled that "business/organizational size" did not have any effect on the 'initiation' and 'use behaviour' of knowledge management system. Such finding is not in line with many past information systems/information technology adoption and diffusion studies. A possible explanation is that the competitive pressure has forced every business and organization practice knowledge management even though there are differences in format, extent, complexity, advances, and experience of their knowledge management activities. Another possible explanation for this is that required technologies (e.g., intranet, databases, communication tools) for managing knowledge is already in place and are available to people. Everyone has thus become familiar with those technologies. As a result, people may tend to take this availability for granted and hence is the indifference to knowledge management system characteristics as an influencing factor in the knowledge management system adoption. On a related note, the results of this study are in line with the findings of $\mathrm{Xu}$ et $\mathrm{al}^{22}$. More research on the impact of business size on information 
systems/information technology adoption and diffusion (or implementation and use) is needed.

This study contributes to the knowledge management literature by developing and testing a knowledge management system use behaviour model. Future research directions include further testing the moderating impact of business size by collecting and analysing larger datasets (e.g., national survey data in Australia and other countries/regions); examining the moderating impact of other factors such as industry/sector, business model, and country/cultural factors; and including more factors in the model (such as competition, customer demand, strategic alliance, voluntariness). It can be certain the results of such studies will be welcomed by both business and academic communities.

\section{References}

1. V. Venkatesh, M.G. Morris, G.B. Davis \& F.D. Davis, User Acceptance of Information Technology: Toward A Unified View, MIS Quarterly, 27 (3) (2003) 425-478.

2. J. Xu, S. Sankaran, G. Sankaran \& D. Clark, Knowledge Management in Twenty-first Century: Literature Review and Future Research Directions, International Technology Management Review, 1(2) (2008) 1-9.

3. A. Serenko, N. Bontis \& T. Hardie, Organizational size and knowledge flow: A proposed theoretical link, Journal of Intellectual Capital, 8 (4) (2007) 610-627.

4. R. Ruggles, The state of the notion: knowledge management in practice, California Management Review, 40 (3) (1998) 80-89.

5. D. Bonner, Leading Knowledge Management and Learning, (American Society of Training \& Development, Virginia, 2000).

6. M. Alavi \& D. E. Leidner, Knowledge management and knowledge management systems: Conceptual foundations and research issues, MIS Quarterly, 25 (1) (2001)107-146.

7. I. Nonaka \& H. Takeuchi, The Knowledge-Creating Company-How Japanese Companies Create the Dynamic of Innovation, (Oxford University Press, New York, 1995).

8. N. Bolloju, M. Khalifa \& E. Turban, Integrating knowledge management into enterprise environments for the next generation decision support, Decision Support Systems, 33 (2) (2002) 163-176.

9. B. Junnarkar \& C. V. Brown, Re-Assessing the Enabling Role of Information Technology in KM, Journal of Knowledge Management, 1 (2) (1997) 142-148.

10. L. L. Bryan \& C. Joyce, The 21 st century organization, McKinsey Quarterly, 3 (2005) 25-33.
11. J. R. Kimberly \& M. J. Evansiko, Organizational Innovation: the influence of individual, organizational, and contextual factors on hospital adoption of technological and administrative innovation, Academy of Management Journal, 24 (4) (1981) 689-713.

12. J. Y. L. Thong \& C. S. Yap, CEO characteristics, organizational characteristics and information technology adoption in small businesses, Omega, 23 (4) (1995) 429442.

13. J. Y. L. Thong, An integrated model of information systems adoption in small business, Journal of Management Information Systems, 15 (4) (1999) 187214.

14. S. Dasgupta, D. Agarwal, A. Ioannidis \& S. Gopalakrishan, Determinants of information technology adoption: an extension of existing models to firms in a developing country, Journal of Global Information Management, 7 (3) (1999) 30-40.

15. G. Premkumar, K. Ramamurthy \& M. Crum, Determinants of EDI adoption in the transportation industry, European Journal of Information Systems, 6 (2) (1997) $107-121$.

16. D. S. Bajwa \& L. Floyd Lewis, Does size matter? An investigation of collaborative information technology adoption by U.S. firms, Journal of Information Technology Theory and Application, 5 (1) (2003) 29-46.

17. E. Ko, S.H. Kim, M. Kim \& J. Y. Woo, Organizational characteristics and the CRM adoption process, Journal of Business Research, 61 (2008) 65-74.

18. E.M. Rogers, E. M. Diffusion of Innovations (Fourth Edition), (The Free Press, New York, USA, 1995).

19. M. Sarvary, Knowledge management and competition in the consulting industry, California Management Review, 4 (2) (1999) 95-107.

20. T. H. Davenport, \& L. Prusak, L., Working Knowledge: How Organizations manage What They Know, (Harvard Business School Press, 1998).

21. K. Sveiby, Small Knowledge Companies-Wave of the Future, 1995, Online Available at: http://www.sveiby.com.au/KnowledgeOrganizationsAust .html [accessed 16 September 1999].

22. J. Xu, M. Quaddus, S. Sankaran \& B. Faranda 2005, Does size matter in knowledge management: A comparison between large organizations and SMEs, Proceedings of the Fifth International Conference on Electronic Business (Hong Kong, December 5-9, 2005) 556-561.

23. K. Y. Wong \& E. Aspinwall, Characterizing knowledge management in the small business environment, Journal of Knowledge Management, 9 (3) (2004) 64-82.

24. D. Lim \& J. Klobas, Knowledge management in small enterprises, The Electronic Library, 18 (6) (2000) 420432.

25. I. Ajzen \& M. Fishbein, Understanding Attitude and Predicting Social Behavior, (Prentice-Hall, Inc., Englewood Cliffs, New Jersey, USA, 1980). 
26. F. D. Davis, A technology Acceptance Model for Empirically Testing New End-User Information Systems: Theory and Results, (Doctoral Dissertation, Massachusetts Institute of Technology, 1986).

27. M. Quaddus \& J. Xu, Adoption and diffusion of knowledge management systems: field studies of factors and variables, Knowledge-based Systems, 18 (2005) 107115.

28. J. P. Bansler \& E. Havn, Exploring the role of networks in IT implementation-The case of knowledge management systems, The Xth European Conference on Information Systems (Gdansk, Poland, June 2002).

29. P. H. Gray, The effects of knowledge management systems on emergent teams: towards a research model, Journal of Strategic Information Systems, 9 (2-3) (2000), 175-191.

30. J. Robertson 2002, Using Usability to Direct KM Systems, Online, Available: http://www.steptwo.com.au/papers/kmc usability/pdf/K MC_Usability.pdf [accessed 2002, Oct. 12].

31. R. L. Thompson, C. A. Higgins \& J. M. Howell, Personal computing: toward a conceptual model of utilization, MIS Quarterly, 15 (1) (1991) 125-143.

32. J. K. Liker \& A. A. Sindi, User acceptance of expert systems: A test of the theory of reasoned action, Journal of Engineering and Technology Management, 14 (2) (1997) $147-173$

33. H. C. Lucas \& V. K. Spitler, Technology use and performance: a field study of broker workstations, Decision Sciences, 30 (2) (1999) 291-311.

34. J. Hartwick \& H. Barki, Explaining the role of user participation in information system use, Management Science, 40 (4) (1994) 440-465.

35. S. Taylor \& P. A. Todd, Assessing it usage: the role of prior experience, MIS Quarterly, 19 (4) (1995) 561-570.

36. G. P. Huber, Transfer of knowledge in knowledge management systems: unexplored issues and suggested studies, European Journal of Information Systems, 10 (2) (2001) $72-79$.

37. A. H. Gold, A. Malhotra \& A. H. Segars, Knowledge Management: An Organizational Capabilities Perspective, Journal of Management Information Systems, 18 (1) (2001) 185-214.

38. J. Ma \& M. Hemmje, Developing a knowledge management systems step by step, Proceedings of 2nd Europe Conference on Knowledge Management, (IEDC Bled School of Management, Bled, Slovenia, November 2001) 301-311.

39. E. J. Pinker \& R. L. VanHorn, Worker incentives to learn in gatekeeper systems: lessons for the implementation of knowledge management systems, Proceedings of the 33rd Hawaii International Conference on System Science, Online, Available at: http://computer.org/proceedings/hicss/0493/04933/04933 027.pdf [accessed March 21, 2002].
40. T. H. Davenport, D. W. Long \& M. C. Beers, Successful knowledge management projects, Sloan Management Review, 39 (2) (1998) 43-57.

41. S. L. Pan \& H. Scarbrough, Knowledge Management in Practice: An Exploratory Case Study, Technology Analysis \& Strategic Management, 11(3) (1999) 359-374.

42. K. Y. Wong \& E. Aspinwall, An empirical study of the important factors for knowledge management adoption in the SME sector, Journal of Knowledge Management, 8 (3) (2005) 44-61.

43. K. B. De Tienne, G. Dyer, C. Hoopes \& S. Harris, Toward a Model of Effective Knowledge Management and Directions for Future Research: Culture, Leadership, and CKOs, Journal of Leadership and Organizational Studies, 10 (4) (2004) 26-43.

44. B. Lioyd \& T. A. Stewart, Leadership and Knowledge Management, Leadership \& Organization Development Journal, 23 (5/6) (2002) 288-292.

45. M. D. Lytras, M. D. A interview with Tom Davenport, AIS SIGSEMIS Bulletin, 2(2) (2005), Online available at:, http://www.sigsemis.org/columns/interviews/Tom_Dave nport_for_SIGSEMIS.pdf [accessed 26 May 2005].

46. D. W. De Long \& L. Fahey, Diagnosing cultural barriers to knowledge management, Academy of Management Executive, 14 (4) (2000) 113-127.

47. K. Y. Wong, Critical success factors for implementing knowledge management in small and medium enterprises, Industry Management + Data Systems, 105 (3) (2005) 261-279.

48. M.R. Lee \& Y. C. Lan, Toward a unified knowledge management model for SMEs, Expert Systems with Applications, 38 (2011) 729-735.

49. H. H. Chen \& C. Pang, Organizational forms for knowledge management in photovoltaic solar energy industry, Journal of Knowledge-based Systems, 23 (2010) 924-933.

50. H. C. Chang, M. T. Tsai \& C. L. Tsai, Complex organizational knowledge structures for new product development teams, Journal of Knowledge-based Systems, 24 (2011) 652-661.

51. A. Brooking, Corporate Memory: Strategies for Knowledge Management, ( International Thomas Business Press, London, UK, 1999).

52. K. Lewin, Group decision and social change, in Readings in Social Psychology, eds T. M. Newcomb \& E. L. Hartley, (Henry Holt, New York, 1952) 459-473.

53. R. L. Nolan, Managing the computer resource: a stage hypothesis, Communications of the ACM, 16 (7) (1973) 399-405.

54. J. Cash \& P. McLeod, Managing the introduction of information systems in strategically dependent companies, Journal of Management Information Systems, 1 (4) (1985) 5-23.

55. D. Gerwin, A theory of innovation process for computeraided manufacturing technology, IEEE Transactions on Engineering Management, 35 (2) (1988) 90-100. 
56. S. L. Huff \& M. C. Munro, Information technology assessment and adoption: a field study, MIS Quarterly, 9 (4) (56) 327-339.

57. T. H. Kwon \& R. W. Zmud, Unifying the fragment models of information systems implementation in Critical Issues in Information System Research, eds R. J. Boland Jr. \& R. A. Hirscheim, (John Wiley \& Sons, New York 1987) 227-251.

58. R. Kanter, When a thousand flowers bloom: structural, collective, and social conditions for innovation in organizations, in Research in Organizational Behavior, eds B. M. Staw \& L. L. Cummings, (JAI Press, Greenwich, CT, 1988) 169-121.

59. R. Walton, Up and Running: Integrating Information Technology and the Organization, (Harvard Business School Press, Boston, 1989).

60. J. C. Brancheau \& J. C. Wetherbe, The adoption of spreadsheet software: testing innovation diffusion theory in the context of end-user computing, Information Systems Research, 1 (2) (1990)123-139.

61. R. B. Cooper \& R. W. Zmud, Information Technology Implementation Research: A Technological Diffusion Approach, Management Science, 36 (2) (1990) 123-139.

62. S. Nilakanta \& R. D. Scamell, The effect of information sources and communication channels on the diffusion of innovation in a data base development environment, Management Science, 36 (1) (1990) 24-40.

63. L. M. Applegate, A case study in the assimilation of technology support for teams, in Computer Augmented Teamwork: A Guided Tour, eds R.P. Bostrom, R.T. Watson \& S. T. Kinney, (Van Nostrand, Reinhold, New York, 1992) 34-62.

64. V. Grover \& M. D. Goslar, The initiation, adoption, and implementation of telecommunication technologies in US organizations, Journal of Management Information Systems, 10 (1) (1993)141-163.

65. A. Rai, External information source and channel effectiveness and the diffusion of CASE innovations: an empirical study, European Journal of Information Systems, 4 (2) (1995) 93-102.

66. F. J. Carter Jr., T. Jambulingam, V. K. Gupta \& N. Melone, Technological innovations: A framework for communicating diffusion effects, Information \& Management, 38 (5) (2001) 277-287.

67. W. Chin and P. R. Newsted, Structural Equation Modeling Analysis with Small Sample Using Partial Least Squares, in Statistical Strategies for Small Sample Research, R. H. Hoyle, Ed, (Thousand Oaks - California: Sage Publication, Inc., 1999)307-341.

68. D. Barclay, C. Higgins \& R. Thompson, The Partial Least Squares (PLS) Approach to Causal Modelling: Personal Computer Adoption and Use as an Illustration, Technology Studies, 2 (2) (1995) 285-309.

69. J. E. Hair, R. E. Anderson, R. L. Tatham \& W. C. Black, Multivariate Data Analysis, Fifth Edition, (Prentice-Hall, Upper Saddle River, USA, 1998). 